\title{
Polarographic Limiting Currents
}

\section{By John Keenan Taylor, Roberta E. Smith, and Irvin L. Cooter}

\begin{abstract}
A cathode-ray oscillograph and special camera were used to record instantaneous values of the current for the dropping-mercury electrode. The results show that the Ilkovic equation does not represent the current as a function of time. The relation between the average current during the life of a drop and that measured by several polarographic circuits was determined.
\end{abstract}

\section{Introduction}

The theory of currents limited by the rate of diffusion of an electrolyzable constituent of a solution to the electrode has been developed by others. For linear diffusion to a plane electrode, the theoretical relation between the instantaneous current, $\left(i_{d}\right)_{i}$, and time, $t_{i}$, is given by $[1,2,3]^{1}$

$$
\left(i_{d}\right)_{i}=A \sqrt{\frac{D}{\pi}} n F C t_{i}^{-1 / 2},
$$

where $A$ is the area of the electrode, $D$ is the diffusion constant, $C$ is the concentration of the diffusing material in the bulk of the solution, $n$ is the number of electrons taking part in the electrode reaction, and $F$ is the Faraday constant. The corresponding equation for a spherical electrode of fixed radius, $R,[1,3]$ is

$$
\left(i_{d}\right)_{i}=A \sqrt{\frac{D}{\pi}} n F C t_{i}^{-1 / 2}+4 \pi R n F D C .
$$

A similar equation for the dropping-mercury electrode $[4,5]$ is

$$
\left(i_{d}\right)_{i}=4\left[\frac{7}{3}\right]^{1 / 2}\left[\frac{3}{4 d}\right]^{2 / 3} \pi^{-1 / 6} n F D^{1 / 2} \mathrm{Cm}^{2 / 3} t_{i}^{1 / 6},
$$

where $d$ is the density of the mercury and $m$ is the mass of mercury emitted by the electrode in unit time.

\footnotetext{
1 Figures in brackets indicate the literature references at the end of this paper.
}

Integration over the life span of a drop of the values of $\left(i_{d}\right)_{i}$ given by eq. 3 gives the expression

$$
i_{d}=k n D^{1 / 2} \mathrm{Cm}^{2 / 3} t^{1 / 6},
$$

where $i_{d}$ is the average current, $t$ is the drop time, and $k$ expresses all of the numerical constants. Equation 4 is used widely in polarographic measurements and referred to as the Ilkovic equation.

Relations between diffusion current and time have been investigated experimentally. Laitinen and Kolthoff [3] found that eq 1 expresses the current for plane electrodes, provided care is taken to eliminate the disturbing effects of convection and adverse density gradients. However, these workers were not able to obtain the predicted behavior with spherical electrodes in aqueous solutions and only approached it in gelatin gels, where disturbances are minimized by the high viscosity of the medium.

No conclusive studies have been made of the current-time relationship for the dropping-mercury electrode. ${ }^{2}$ Ilkovic [6] made some measurements and states that the data are represented by a parabola of approximately the sixth order. However, he does not give sufficient details of his experiments to permit a recalculation of the data. Most of the tests of the Ilkovic equation fall into

\footnotetext{
2 Since this paper was prepared, Hugh A. McKenzie reported some work to us in which he found current-time curves that were approximately onethird order parabolas. A preliminary report of his work has been published (J. Am. Chem. Soc. 70, 3147 (1948). Also, we have been informed that F. L. Steghart read a paper to the Physical Methods Group of the Society of Public Analysts at London on December 12, 1947, in which he reported current-time curves which did not follow the Ilkovic equation.
} 
two groups. The first consists in measurements or calculation of all of the parameters of the equation and comparing the diffusion current calculated with that observed [7]. The second consists in determining the constancy of the diffusion current constant, $I=i_{d} / \mathrm{Cm}^{2 / 3} t^{1 / 6}$, as $C, m$, and $t$ are varied [8]. All of these experiments have been performed while using highly damped apparatus for the electrical measurements, the assumption being made that average currents were measured.

The present paper reports the results of some experiments designed to determine the currenttime relationship for the dropping-mercury electrode. Because of their practical interest, the relations between the average currents, and those measured by several polarographic circuits also have been determined.

\section{Experimental Details}

A schematic diagram of the circuits and apparatus used for measuring the polarographic diffusion currents as a function of time is shown in figure 1 . In this figure, $P_{1}$ is a Leeds \& Northrup portable potentiometer for supplying the voltage for the circuit, which consists of the polarographic cell and the calibrated resistance box, $R_{1}$. When the selector switch, $S_{1}$, is on the "measure" position, the voltage drop across $R_{1}$, after amplification, deflects the beam of a cathode-ray tube. A photographic record of the deflection of the beam as a function of time is made by means of the drum camera.

As the voltage across $R_{1}$ is only a few millivolts, and the voltage required on the deflection plates of the oscillograph is approximately 100 volts, an amplification factor of several thousand is required. Moreover, this amplification factor should remain constant over the range of applied voltage and during the recording time of several seconds. These requirements were met by using a directcoupled amplifier designed at the David W. Taylor Model Basin [9]. This amplifier, which has only resistance coupling so that it can be used with aperiodic phenomena, has an amplification factor of $1,000,2,000$, or 5,000 , with uniform response in the frequency range from 0 to $50,000 \mathrm{c} / \mathrm{s}$. The output of this amplifier is connected directly to the vertical deflection plates of a $\mathrm{Du}$ Mont cathode-ray oscillograph, type 208. The photographic record of the deflection of the beam of the

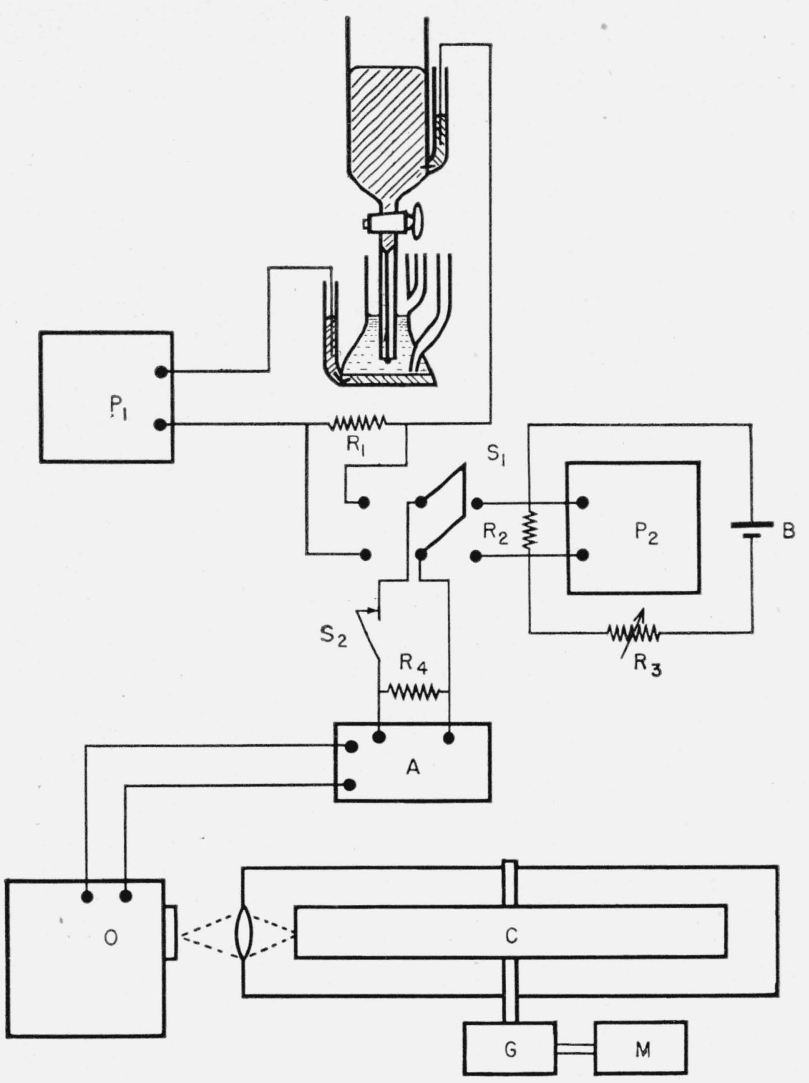

Figure 1. Apparatus used for measuring limiting current.

$P_{1}, P_{2}$, potentiometers; $R_{1}, R_{2}$, resistance boxes; $R_{3}$, current-limiting resistor; $R_{4}$, stabilizing resistor; $S_{1}$, selector switch; $S_{2}$, tapping key; $B$, battery, $1.5 \mathrm{v} ; A$, amplifier; $O$, oscillograph; $C$, camera; $G$, reduction gear; $M$, motor.

cathode-ray tube is made by a drum camera. Essentially, this camera consists of a lens and shutter mounted in a light-tight housing enclosing a drum having a circumference of $60 \mathrm{in}$. and a rim 4 in. wide. The drum is mounted on a vertical axle and is belt-driven by a direct-current motor through reduction gears. When the drum is rotating at $2 \mathrm{rpm}$, the peripheral speed is approximately $2 \mathrm{in} . / \mathrm{sec}$. The housing can be opened to permit the mounting of a film on the drum.

For the electrodes used in these experiments, the time of each drop was approximately $3.5 \mathrm{sec}$, so that the diffusion current record for each drop extended about 7 in. on the film; this permitted records of seven or eight successive drops on each film.

In order that the recorded amplitude of the diffusion current at any point represent the true amplitude, it is necessary that the reference line for zero current remain constant during the re- 
cording for each drop. Since there is a small but significant drift of the zero position of the amplifier during the $30 \mathrm{sec}$ of recording, it is necessary to record a sufficient number of zero positions during this interval to establish a reliable reference line. A simple means of doing this is to incorporate a tapping key, $S_{2}$, into the input circuit of the amplifier, between $R_{3}$ and $R_{1}$. The normal position for this switch is closed, but by tapping the key the external circuit of the amplifier can be periodically opened for a short time interval. Linear interpolation between the various zero marks was used to determine the zero level corresponding to a given deflection.

The correlation of the recorded amplitude with the voltage producing the deflection was obtained by means of the calibrating circuit, consisting of a battery, $B$, a current-limiting resistor, $R_{3}$, and a calibrated resistance box, $R_{2}$. With selector switch, $S_{1}$, on the "calibrate" position, known voltage was applied to the amplifier by means of the calibrating circuit. By means of the currentlimiting resistor, the voltage drop across $R_{2}$ was adjusted so that measurable potentials are applied to the amplifier input. These potentials were so selected that, without changing the gain controls of the amplifier, the deflection due to the calibrating voltage covered, in several steps, the maximum range of the deflection due to the polarographic current. These calibrating voltages were measured with the precision potentiometer, $P_{2}$. The deflection of the cathode-ray oscillograph beam due to these calibration voltages was recorded on the same film immediately after the recording of the polarographic current. From the magnitude of the calibrating voltages and the resulting measured deflections, a calibration curve may be obtained by plotting sensitivity $(\mathrm{mv} / \mathrm{cm}$.) with respect to the deflection in centimeters of the oscilloscope. From the calibration curve, the measured deflection due to the polarographic current, and the value of $R_{1}$ and $\mathrm{R}_{4}$, it is possible to calculate the diffusion current.

A calibration factor for converting length measurement along the film to time was obtained by measuring the average drop rate of the electrode and dividing this by the average measured length of the current-time curve for a number of drops. This quotient, when multiplied by the measured length interval, would give the time interval. Care was taken to make the vertical axis of the oscillograph-beam deflections parallel to the axis of rotation of the drum in order to eliminate timing errors, which might otherwise occur.

The current-time records were measured on a special comparator. The comparator consisted of a heavy metal bed, $4 \mathrm{ft}$. long on which rested a traveling carriage. The carriage, driven by a screw with a graduated head, had a range of about $90 \mathrm{~cm}$ of longitudinal motion. Two long glass plates for holding the film, illuminated from below by a green fluorescent light, were set about $2 \frac{1}{2}$ in. below the carriage and parellel to it. On the carriage itself was the observing microscope, supported on a micrometer slide. The observing microscope, of magnification $4 \times$, contained the reference cross hairs. By the use of this comparator, values of the abscissa (time) and ordinate (current) could be measured with a precision of a few microns.

The solution used for the oscillographic measurements was 3.018 millimolar in cadmium, 0.1 molar in potassium chloride, and contained 0.01 percent of gelatin to suppress maxima. A similar solution, except for the cadmium concentration, which was 2.724 millimolar, was used in all of the other work. These solutions were made with known amounts of cadmium metal and checked by analysis.

A silver wire wrapped around the droppingmercury electrode served as the anode in all but a few cases where the mercury pool was employed. Diffusion-current measurements for cadmium were made at the potential $-0.9 \mathrm{v}$ with respect to the silver-silver-chloride anode. The droptime, $t$, of the electrode was determined at this potential as was also the flow, $m$, of mercury from the capillary. It was found that the value of $m$ in the solution and at this value of the applied potential was about 4 percent smaller than when measured in air, in agreement with previous investigators [10].

Purified nitrogen was used to free all of the solutions of oxygen. The diffusion-current measurements were made in a thermostated bath at $25^{\circ} \mathrm{C}$.

\section{Results}

A number of current-time curves were obtained in which the zero was marked on the film after the recording of current, but the slight drift of the amplifier was sufficient to preclude their use in quantitative calculations. The qualitative con- 


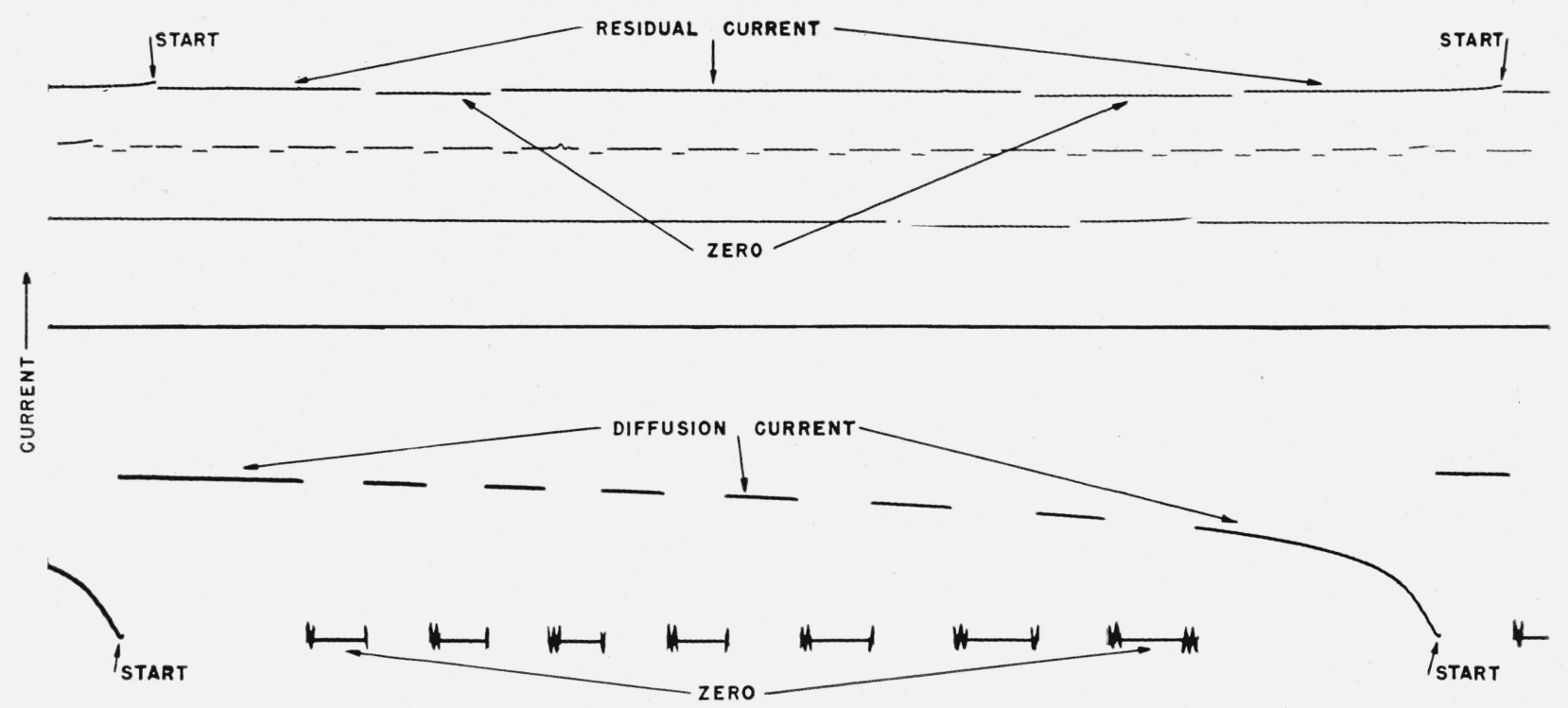

TIME

FiguRE 2. Typical photographic records of residual current and diffusion current.

The upper portion shows three traces for the residual current (one labeled), whereas the lower portion shows one trace of the diffusion current. The start of each new drop is indicated, and the time interval between each of such designations is about 3.5 sec.

clusions drawn from them are, however, in agreement with and support the more precise observations.

Several experiments were performed in which the zero was put on the film during the measurements of the limiting current. However, wherever a zero mark occurred, no record of the limiting current was obtained, so that some of the records were spoiled. Thus the start, or ending of a particular drop, or the portion of the curve where the current was changing most rapidly might be missing. Any of these defects was sufficient reason for discarding the measurement. As a result, only the complete records of two drops were accepted and used for quantitative interpretation. A number of the other traces were used for measurements of the value of the maximum current, however, or for the study of selected portions of the current-time curve.

A portion of the photographic record is shown in figure 2. The ordinate increases in the usual direction, but the time axis increases in the right to left direction. Three traces of the residual current are shown in the upper part of the figure. The current will be observed to start at a high value and to decrease with time, the zero trace being always below the residual current line. The polarographic limiting current is shown in the lower part of the figure. This current is not zero at the start of the drop but goes through a minimum, and then increases rapidly at first and more slowly later until the drop is disengaged from the capillary. Figures 3 and 4 are large scale plots of

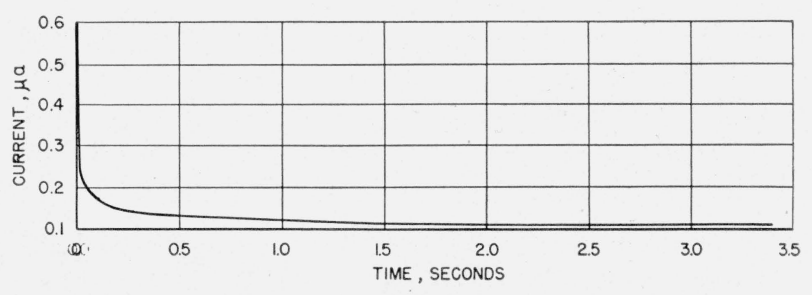

Figure 3. Plot of residual current.

the residual current and limiting current, respectively. The initial behavior of the limiting current is due to the residual current being greater than the limiting current during the very early period of drop formation. When the instantaneous value of the residual current is subtracted from the corresponding value for the limiting 


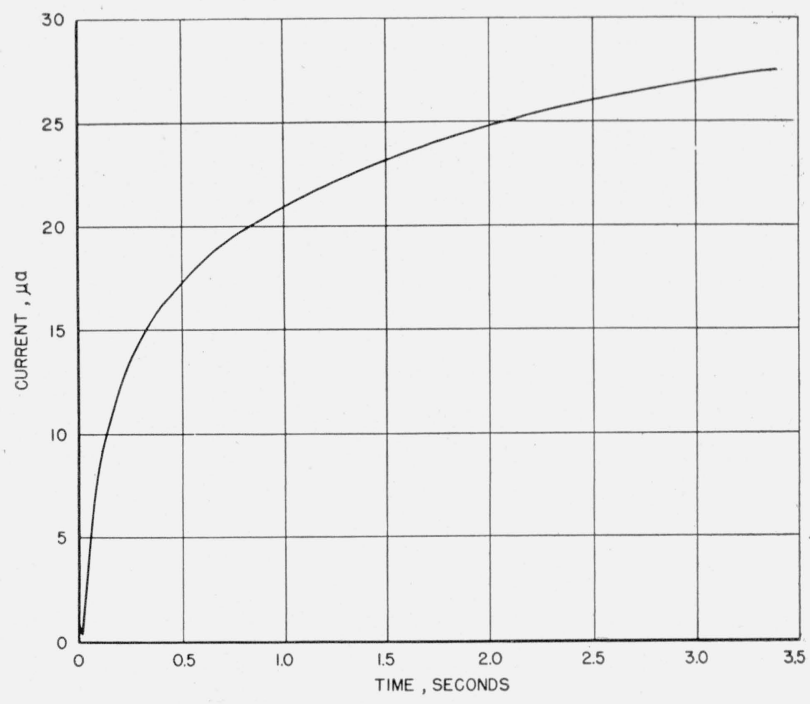

Figure 4. Plot of limiting current.

TABLE 1. Variation of diffusion current with time for drop one

$t=3.392 \mathrm{sec} ; m=2.305 \mathrm{mg} / \mathrm{sec} ; C=3.018$ millimole/liter

\begin{tabular}{|c|c|c|c|c|c|}
\hline Abscissa & Deflection & Time & $\begin{array}{c}\text { Limiting } \\
\text { current, } \\
i_{l}\end{array}$ & $\begin{array}{c}\text { Residual } \\
\text { current, } \\
i_{r}\end{array}$ & $\begin{array}{c}\text { Diffusion } \\
\text { current, } \\
2_{d}\end{array}$ \\
\hline Turn & $\mathrm{cm}$ & $\mathrm{sec}$ & $\mu a$ & $\mu a$ & $\mu a$ \\
\hline 0 & 0.054 & 0 & 0.60 & 0.60 & 0.00 \\
\hline 0.128 & .031 & 0.005 & .34 & .29 & .05 \\
\hline .237 & .045 & .009 & .49 & .27 & .22 \\
\hline .363 & .061 & .013 & .67 & .25 & .42 \\
\hline .506 & .104 & .018 & 1.14 & .24 & .90 \\
\hline .673 & .179 & .025 & 1.96 & .23 & 1. 73 \\
\hline 1. 347 & .399 & .049 & 4. 40 & .20 & 4. 20 \\
\hline 2. 061 & .625 & .076 & 6. 93 & .19 & 6. 74 \\
\hline 2.828 & .794 & .104 & 8.84 & .17 & 8. 67 \\
\hline 4. 176 & .989 & .153 & 11. 07 & .16 & 10.91 \\
\hline 5. 576 & 1. 124 & .204 & 12.63 & .15 & 12.48 \\
\hline 8. 076 & 1. 291 & .296 & 14. 56 & .14 & 14.42 \\
\hline 12.576 & 1. 494 & .461 & 16. 94 & .13 & 16.81 \\
\hline 17. 306 & 1. 634 & .635 & 18. 60 & .13 & 18.47 \\
\hline 23.544 & 1. 766 & .863 & 20.17 & .12 & 20.05 \\
\hline 28.312 & 1.845 & 1. 038 & 21.11 & .12 & 20.99 \\
\hline 39. 576 & 2.005 & 1.451 & 23.03 & .11 & 22.92 \\
\hline 54. 669 & 2. 164 & 2.005 & 24.94 & .11 & 24.83 \\
\hline 66. 704 & 2. 253 & 2.446 & 26.05 & .11 & 25.94 \\
\hline 80.086 & 2.325 & 2. 937 & 26. 92 & .11 & 26.81 \\
\hline 92.487 & 2. 371 & 3.392 & 27.49 & .11 & 27.38 \\
\hline
\end{tabular}

current, the resulting diffusion current starts at zero within the error of the experiment.

The photographic records were measured in the manner described, and the abstracted data are given in tables 1 and 2 . The first column contains the abscissa readings in turns of the lead screw of the comparator, and the second column gives
TABLE 2. Variation of diffusion current with time for drop two

$t=3.488 \mathrm{sec} ; m=2.305 \mathrm{mg} / \mathrm{sec} ; C=3.018$ millimole/liter

\begin{tabular}{|c|c|c|c|c|c|}
\hline Abscissa & Deflection & Time & $\begin{array}{l}\text { Limiting } \\
\text { current, } \\
i_{l}\end{array}$ & $\begin{array}{c}\text { Residual } \\
\text { current, } \\
i_{r}\end{array}$ & $\begin{array}{l}\text { Diffusion } \\
\text { current, } \\
i_{d}\end{array}$ \\
\hline Turn & $\mathrm{cm}$ & $\sec$ & $\mu a$ & $\mu a$ & $\mu a$ \\
\hline 0 & 0.056 & 0 & 0.62 & 0.60 & 0.02 \\
\hline 0.160 & .035 & 0.006 & .38 & .27 & .11 \\
\hline .331 & .055 & .012 & .60 & .25 & .35 \\
\hline .548 & .119 & .020 & 1.31 & .24 & 1.07 \\
\hline .728 & .178 & .027 & 1.95 & .23 & 1. 72 \\
\hline 1. 468 & .440 & .054 & 4.86 & .21 & 4. 65 \\
\hline 1. 969 & .595 & .072 & 6.59 & .19 & 6.40 \\
\hline 2. 718 & .759 & .100 & 8.44 & .18 & 8.26 \\
\hline 3.968 & .946 & .145 & 10.58 & .16 & 10.42 \\
\hline 5. 468 & 1.095 & .200 & 12. 29 & .15 & 12. 14 \\
\hline 8. 468 & 1. 293 & .310 & 14. 53 & .14 & 14.44 \\
\hline 10. 468 & 1.390 & .384 & 15. 72 & .13 & 15. 59 \\
\hline 13.510 & 1. 509 & .495 & 17.11 & .13 & 16. 98 \\
\hline 19. 598 & 1. 683 & .719 & 19.18 & .12 & 19. 06 \\
\hline 28. 968 & 1. 860 & 1. 062 & 21. 29 & .12 & 21.17 \\
\hline 40.019 & 2. 013 & 1. 468 & 23.13 & .11 & 23.02 \\
\hline 54.914 & 2.147 & 2.014 & 24.75 & .11 & 24.64 \\
\hline 65.716 & 2. 246 & 2.410 & 25. 96 & .11 & 25.85 \\
\hline 81.531 & 2.338 & 2. 990 & 27.09 & .11 & 26.98 \\
\hline 95.133 & 2.397 & 3.488 & 27.81 & .11 & 27.70 \\
\hline
\end{tabular}

the corresponding deflection of the oscilloscopic spot from its zero position. The third column gives the elapsed times from the beginning of the drop, which were obtained by multiplying column one by the abscissa factor. The values for the limiting current, $i_{l}$, in column four resulted from multiplying the deflection by the corresponding sensitivity for that deflection found from the calibration curve. The residual current, computed in a like manner, was plotted on a large scale as a function of time, and values corresponding to the tabulated values of time were read and recorded in column five. Values for the diffusion current, $i_{d}$, in column six are the differences of columns four and five.

Figure 5 is a plot of the logarithm of the current with respect to the logarithm of the time. For conformance with the Ilkovic equation, the plot should be linear with a slope numerically equal to one-sixth. The plot is not linear, and a comparison with the slopes drawn in the figure shows that it never reached this value at any time during the life of the drop. This is emphasized by the mathematical treatment in which the function $i_{d}=k t^{n}$, in its logarithmic form, was adjusted to the data by the method of least squares. When the entire range of the measurements was used, the value for 


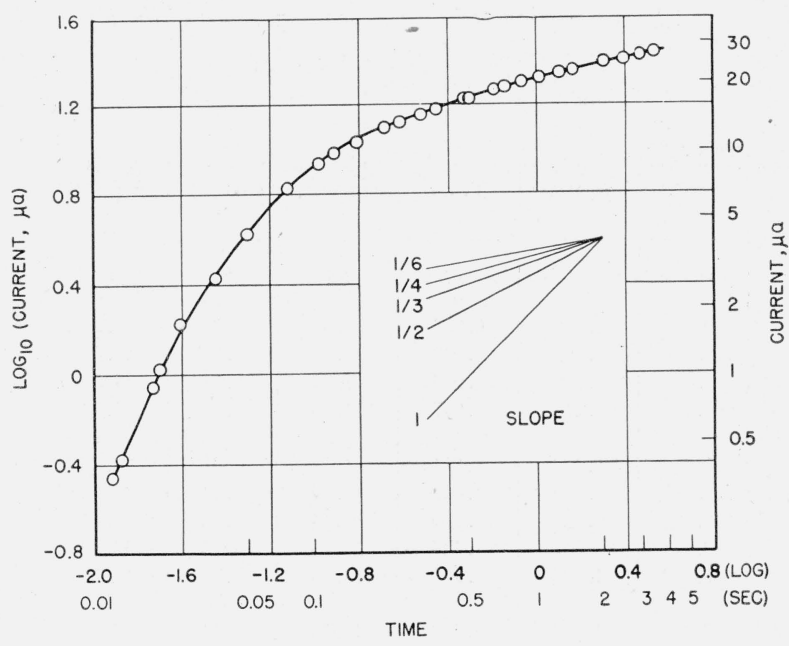

Figure 5. Logarithmic plot of diffusion current with respect to time.

exponent $n=0.82$ was obtained, but the fit was extremely poor. In the range $0.1 \mathrm{sec}$ to maturity, the value, $n=0.31$, was found with an average deviation of \pm 4.5 percent. For all times greater than 0.5 sec there resulted $n=0.249$, with an average deviation of \pm 0.97 percent, whereas in the more limited range of 1 sec or greater, $n=$ 0.227 , and the average deviation was \pm 0.70 percent. Jf times greater than 2 sec are used for the calculation, the exponent became $n=0.186$, and the average deviation was \pm 0.30 percent. A number of attempts were made to fit other simple equations of various types to the data, but none was found satisfactory.

The average current is of interest, since this is the quantity to be expected to be measured when using highly damped galvanometers or other measuring instruments. Accordingly, large-scale plots were made of the data for two drops, and the average current was found by graphical integration. For drops having maximum currents of 27.37 and $27.70 \mu \mathrm{a}$, respectively, the corresponding average currents were $22.1_{7}$ and $22.3_{0} \mu \mathrm{a}$. The ratios of the average to the maximum current were $0.81_{0}$ and $0.80_{5}$ in the two cases, which are to be compared with the value 0.859 (6/7) found from integration of the Ilkovic equation. Integration of the equation $i_{d}=k t^{0.249}$ gives $0.80_{1}$ for the ratio, in good agreement with the graphical integration. Although this latter equation does not fit the data during the early time of drop formation, the bulk of the area under the curve occurs during the time when the fit is good, which explains the agreement of the value found by integration with that obtained by graphical means.

Calculation of the diffusion-current constant [11], $I$, defined by the expression $I=i_{\mathrm{d}} / \mathrm{Cm}^{2 / 3} t^{1 / 6}$ is a satisfactory means of reducing experiments done under slightly different conditions to a common basis, since this expression has been shown to hold true for widely varying characteristics of the electrode. When the maximum current is inserted in the expression, the constant $I_{\max }=4.25$ is obtained whereas the average current yields the value $I=3.44$.

Less precise but confirmatory evidence for the deviation of the experimental current-time curve from that of the Ilkovic equation was obtained from measurements with a Hathaway galvanometer oscillograph, model 58 B. A chart speed of $28 \mathrm{~mm} / \mathrm{sec}$ was used, and the galvanometer had a sensitivity of $0.38 \mu \mathrm{a} / \mathrm{mm}$ and a frequency response of $20 \mathrm{c} / \mathrm{s}$, permitting a faith-

TABLE 3. Diffusion-current constants from measurements with the galvanometer oscillograph

\begin{tabular}{|c|c|c|c|}
\hline Solution & $I_{\operatorname{cax}}$ & $I$ & $I / I_{\max }$ \\
\hline Cadm:um . & 4. 20 & 3.42 & $0.81_{3}$ \\
\hline Lead _.. & 4. 81 & 3.86 & $.80_{2}$ \\
\hline
\end{tabular}

ful record of the current for all but about the first 0.2 -sec period of the life of the drop. The apparatus was calibrated in a manner similar to that used in the work with the cathode-ray oscillograph, and diffusion-current measurements were made on the cadmium solution already described and on a solution 3 millimolar in lead, with $1-N$ hydrochloric acid as the supporting electrolyte. From values of the maximum current and of average current obtained from graphical integration of the curves, extrapolated to zero time, diffusion-current constants were calculated. The results are given in table 3 . (The extrapolation introduces no significant error in integration, since the area under this part of the curve is a small fraction of the total area.)

The residual current, $i_{r}$, may be considered to be composed of a faradayic current, $i_{f}$, and a condenser current, $i_{c}$. The former is the sum of the diffusion currents due to reducible impurities in the solution, whereas the latter arises as the result of charging or discharging the condenser resulting from the double layer at the mercury-solution 
interface. The condenser current at any time, $t$, during the life of a drop should be expressed by $i_{c}=k t^{-1 / 3}$, where $k$ represents the product of the capacity of the double layer, the difference between the applied potential and that of the electrocapillary maximum, and geometrical constants [12, 13]. Accordingly a plot of the logarithm of the residual current with respect to the logarithm of the time should be linear with slope equal to minus onethird. Such a plot is given in figure 6 and is seen to be linear, but the slope is only one-half of the theoretical value. Although pure materials were used for the supporting electrolyte and care was exercised to remove oxygen from the solutions, it is possible that there may have been some contribution of $i_{f}$ to the residual current. The present experiments do not permit conclusions as to the reason for the discrepancy.

It is of interest to determine the magnitude of the current measured by various types of polarographic apparatus and to study how this depends upon the constants of the measuring instrument. The simplest apparatus is one in which a reflecting galvanometer is placed in series with the cell and the deflection read with the conventional lamp and scale. It is well known that galvanometers may be used to integrate the current. In the measurement of asymmetrical periodic phenomena with highly damped instruments or ones whose period during operation is long with respect to that of the event observed, the excursions of the galvanometer spot around an average position are small when compared with the total deflection, and the midpoint of the oscillation should approxi-

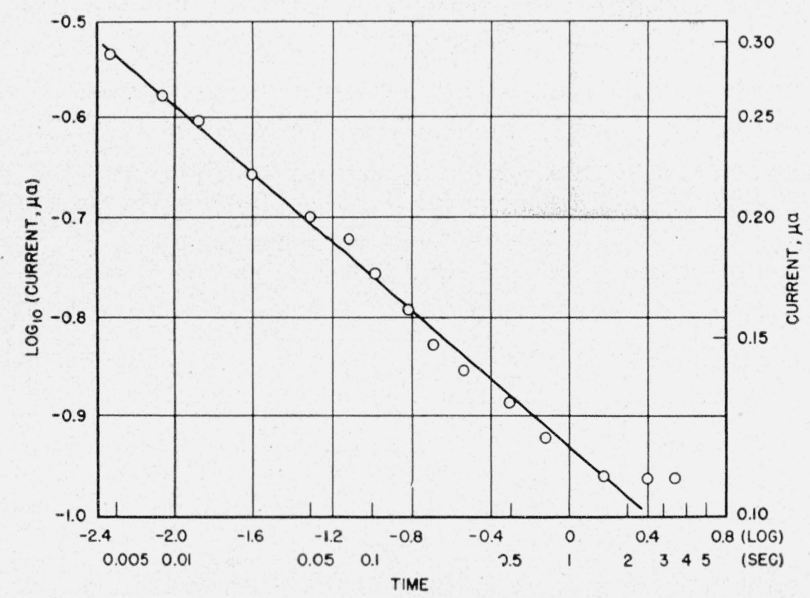

FIGURE 6. Logarithmic plot of residual current with respect to time.
TABLE 4. Dependence of the diffusion current on the characteristics of the galvanometer

In column 2 , the values in italic type indicate the critical damping resistance

\begin{tabular}{|c|c|c|c|c|c|}
\hline $\begin{array}{l}\text { Galvanometer } \\
\text { period }\end{array}$ & $\begin{array}{l}\text { Damp- } \\
\text { ing re- } \\
\text { sistance }\end{array}$ & $\begin{array}{c}\text { Average } \\
\text { deflec- } \\
\text { tion }\end{array}$ & $\begin{array}{l}\text { Oscilla- } \\
\text { tion }\end{array}$ & $\begin{array}{l}I \text { (aver- } \\
\text { age de- } \\
\text { flection) }\end{array}$ & $\begin{array}{l}I \text { (inte- } \\
\text { grated } \\
\text { deflec- } \\
\text { tion) }\end{array}$ \\
\hline \multirow{8}{*}{1.85} & Ohm & $\mathrm{cm}$ & $\mathrm{cm}$ & & \\
\hline & $\infty$ & 5. 87 & 5.5 & 2. 99 & 3.48 \\
\hline & 500 & 5. 82 & 4. 7 & 2. 93 & 3.34 \\
\hline & 200 & 5. 65 & 3.9 & 3.02 & 3.39 \\
\hline & 100 & 6.98 & 4. 7 & 3.14 & 3.34 \\
\hline & 43 & 5. 81 & 2. 7 & 3.27 & 3.35 \\
\hline & 10 & 7. 58 & 2.1 & 3.53 & 3. 53 \\
\hline & 5 & 4. 35 & 1.1 & 3.45 & 3.45 \\
\hline \multirow{3}{*}{2.0} & $\infty$ & 14. 50 & 6.4 & 3.07 & 3.40 \\
\hline & $\infty$ & 25.43 & 12. 0 & 3.28 & 3.46 \\
\hline & 50 & 35.75 & 18. 0 & 3. 20 & - \\
\hline \multirow{4}{*}{$4.7 .}$. & 10 & 30.88 & 7. 0 & 3.47 & - \\
\hline & 5 & 36.00 & 6.0 & 3.47 & - - - \\
\hline & 2 & 17. 18 & 2. 6 & 3.45 & - \\
\hline & 1 & 9.44 & 1.3 & 3.45 & - . \\
\hline \multirow{5}{*}{5.0 . } & $\infty$ & 24.80 & 7. 6 & 3.50 & ..... \\
\hline & 500 & 23.61 & 7. 0 & 3.50 & -... \\
\hline & 40 & 23.04 & 3.7 & 3.50 & - \\
\hline & 10 & 21.32 & 2. 2 & 3.45 & - . \\
\hline & 1 & 21.06 & 1. 7 & 3.48 & - . \\
\hline \multirow{3}{*}{6.4} & 11 & 22.23 & 3.9 & 3.46 & ...... \\
\hline & 5 & 19. 21 & 3.0 & 3.41 & - \\
\hline & 1 & 25. 80 & 3.5 & 3.43 & ..... \\
\hline 15.5 & 21,000 & 19.45 & .5 & 3.47 & -... \\
\hline
\end{tabular}

mate the average current. With relatively shortperiod equipment, this method is no longer adequate.

The results of measurements with several galvanometers are reported in table 4. Galvanometers with the periods indicated in column 1 were damped with the resistances across the terminals shown in column 2. The average deflection is shown in column 3 , whereas column 4 gives the values of the corresponding total oscillations of the galvanometer spot. The diffusion-current constants of column 5 were calculated by using the midpoints of the oscillations as the average current. For the short-period galvanometers, an attempt was made to determine the variation of the galvanometer oscillation with time by observing the time when the galvanometer spot crossed selected points on the scale. The resulting data were plotted, integrated graphically, and the values in column 6 were calculated by using the average currents so obtained.

It is interesting to note that those instruments that had a period several times that of the dropping electrode or were highly damped gave essentially the same values for $I$ when calculated from the midpoints of the galvanometer oscillations. 
The galvanometer of period $1.85 \mathrm{sec}$ was of the enclosed spotlight type with a short scale, so that only small deflections could be observed with a corresponding low precision. The data, however, are conclusive in showing that, except for the highly damped condition, low values are obtained when the midpoints of the oscillations are used to calculate the current. If the wave form of the oscillation is known, however, the integrated current is in satisfactory agreement with that found with galvanometers of relatively long period, and with the true average current found in the studies with the oscillograph.

Diffusion currents can be determined from measurement of the potential drop across a known resistance. This potential varies throughout the life of the drop, and hence an average value is usually measured. The potentiometric balance, using as a criterion the symmetrical oscillations of the galvanometer, is influenced by the characteristics of the indicating instrument. Data illustrating this dependence are given in table 5 . The spotlight

TABLE 5. Dependence of the diffusion current measured potentiometrically on the characteristics of the galvanometer

\begin{tabular}{|c|c|c|c|}
\hline $\begin{array}{c}\text { Damping } \\
\text { resistance }\end{array}$ & $\begin{array}{c}\text { Limiting } \\
\text { current }\end{array}$ & $\begin{array}{c}\text { Diffusion } \\
\text { current }\end{array}$ & $I$ \\
\cline { 1 - 2 } Ohm & $\mu a$ & $\mu a$ & \\
$\infty$ & 17.0 & 16.9 & 2.90 \\
500 & 17.2 & 17.1 & 2.93 \\
100 & 18.5 & 18.4 & 3.16 \\
50 & 19.2 & 19.1 & 3.28 \\
25 & 19.9 & 19.8 & 3.40 \\
10 & 20.1 & 20.0 & 3.43 \\
1 & 20.2 & 20.1 & 3.45 \\
& & & \\
\hline
\end{tabular}

galvanometer of period $1.85 \mathrm{sec}$ was used and damped as indicated. The diffusion-current constant found for the highly damped experiments was 3.44 , which is in excellent agreement with that found for the average current. On the basis of these and other experiments not reported, it may be concluded that the same considerations as found for the direct measurement of current apply to galvanometers used to indicate potentiometric balance.

An interesting confirmation of the potentiometric experiments is given by some measurements with the Speedomax potentiometer to record the potential drop across a $200-\mathrm{ohm}$ resistance in series with the cell. The apparatus used required $1 \mathrm{sec}$ to complete a full-scale deflection of $25 \mathrm{~cm}$ and had a chart speed of $4 \mathrm{in} . / \mathrm{min}$. In the particular experiments a maximum deflection of $24 \mathrm{~cm}$ was obtained, and the magnitude of the oscillations was $9 \mathrm{~cm}$. By using the average oscillation for determining the average current, the low value of the diffusion-current constant of 3.32 was obtained. After graphical integration of the potential-time curves, a diffusion-current constant of 3.49 was found, which is in fair agreement with the true average value, considering the precision of the measurement.

Several models of commercial polarographs were used to measure the diffusion current of the cadmium solution used in the experiments with the oscillograph. The current sensitivities of these were determined under the exact conditions of use by measuring the recorded deflection produced by a known current, the latter being determined by measuring the potential drop across a standard resistance. Corrections for residual current were made by both graphical and exact methods. With the Heyrovsky model VIII instrument the value for $I=3.42$ was found, whereas with a SargentHeyrovsky model XII polarograph a large number of measurements gave $I=3.43$.

A Sargent model XX instrument was also used for determining diffusion currents. This apparatus is provided with circuit elements to damp electrically the oscillations of the recorder caused by the periodic growth of the drop. The degree of damping may be varied from position 1, undamped except for the natural period of the recorder, to position 5, which introduces the maximum damping. The cadmium solution already described and a solution 3 millimolar in lead in a supporting electrolyte of $1-N$ hydrochloric acid were studied, and the average of a number of determinations gave the results in table 6 . The

TABLE 6. Diffusion-current constants from measurements with a Sargent model $X X$ polarograph

\begin{tabular}{|c|c|c|c|c|c|}
\hline \multirow{2}{*}{ Solution } & \multicolumn{5}{|c|}{ Damping position } \\
\hline & 1 & 2 & 3 & 4 & 5 \\
\hline Cadmium.- & 3.52 & 3.48 & 3.55 & 3.57 & 3.57 \\
\hline Lead - . & 4. 03 & 3.93 & 4.01 & 4. 05 & 4.05 \\
\hline
\end{tabular}

constants for both solutions are somewhat higher than those found for the other types of apparatus. The circuit constants were such that even with the 
maximum damping, large oscillations of the recorder were observed. Lingane [14] has reported that this apparatus gives high values for diffusion current under such a condition, which may explain the results found.

Schulman Battey, and Jelatis [15] have described apparatus that incorporates a current rerecorder of low damping. An instrument of this design, now marketed under the trade name, Polaro-analyzer, was loaned to the authors for this work. The Esterline-Angus recorder used gives a full-scale deflection in about $0.5 \mathrm{sec}$. Although this is too slow to give a faithful record of the current during the early period of formation of a drop, the response is adequate to follow the current in the later stages of drop growth, when using drop times of the order of 3 sec. With the 3 -millimolar cadmium solution, the value $I_{\max }=$ 4.11 was found. By using the damping circuit with which the apparatus is equipped, the ratio of the average to the maximum current was found to be 0.82 , in satisfactory agreement with the values found when using the oscillograph. It is concluded that the peak current found with this apparatus corresponds to the maximum current within a few percent.

\section{Conclusions}

The results of this investigation are conclusive in showing that the Ilkovic equation does not represent the instantaneous current for the dropping-mercury electrode. The deviation is greatest at the start of drop formation but is appreciable at all times. Part of the deviation may be due to an unsymmetrical diffusion field resulting from mechanical screening by the body of the capillary. Density gradients at the surface of the electrode may exert disturbances similar to those observed by Laitinen and Kolthoff for solid spherical electrodes. Experiments are now being planned in which capillaries with substantially the same droprate but with different values of $m$ will be studied. These and other investigations may yield valuable information concerning the nature of the deviations.

Although the Ilkovic equation does not represent the instantaneous current, several investigators have shown that it explains, quantitatively, the variation of the diffusion current with concentration of electrolyzable constituent and with the characteristics of the electrode, provided a sufficient concentration of suppresser of maxima is present [8] and electrodes with very small drop times are not used [16]. The conditions governing the quantitative use of diffusion-current constants have been reviewed in a previous paper [17]. To these should be added the precaution to make sure that precise values of either maximum or average current are measured by the apparatus. A preferable procedure is for each worker to determine his own values for the constants to be used. The individual idiosyncrasies of the equipment and personal errors of the observer have the least effect in this manner.

\section{References}

[1] F. G. Cottrell, Z. physik. Chem. 42, 385 (1902).

[2] D. MacGillavry and E. K. Rideal, Rec. trav. chim. 56, 1013 (1937).

[3] H. A. Laitinen and I. M. Kolthoff, J. Am. Chem. Soc. 61, 3344 (1939).

[4] D. Ilkovic, Coll. Czechoslov. Chem. Commun. 6, 498 (1934).

[5] I. M. Kolthoff and J. J. Lingane, Polarography, p. 362 (Interscience Pub. Inc., New York, N. Y., 1941).

[6] D. Ilkovic, Coll. Czechoslov. Chem. Commun. 8, 31 (1936).

[7] J. J. Lingane and 1. M. Kolthoff, J. Am. Chem. Soc. 61, 825 (1939).

[8] F. Buckley and J. K. Taylor, J. Research NBS 34, 97 (1945) RP1631.

[9] G. R. Mezger, Electronics 17, 126, 254 (1944).

[10] J. J. Lingane and B. A. Loveridge, J. Am. Chem. Soc. 66, 1425 (1944).

[11] J. J. Lingane, Ind. Eng. Chem., Anal. Ed. 15, 583 (1943).

[12] J. Heyrovsky, Polarographie, p. 55 (Springer, Vienna, 1941).

[13] I. M. Kolthoff and J. J. Lingane, Polarography, p. 108 (Interscience Pub. Inc., New York, N. Y., 1941).

[14] J. J. Lingane, Ind. Eng. Chem., Anal. Ed. 18, 734 (1946).

[15] J. H. Schulman, H. B. Battey, and D. G. Jelatis, Rev. Sci. Instr. 18, 226 (1947).

[16] J. J. Lingane and B. A. Loveridge, J. Am. Chem. Soc. 68, 395 (1946).

[17] J. K. Taylor, Anal. Chem. 19, 368 (1947).

Washington, December 10, 1948. 